\title{
Grassland Research in the British Empire.
}

THROUGHOUT the British Empire there are vast 1 tracts of natural pastures which produce herbage of an inferior nutritive value. A large body of evidence has been accumulated in recent years to show that this low nutritive value is to be correlated with deficiencies of inorganic constituents, such as calcium, phosphorus, and chlorine, in the herbage, a condition which is the outcome of growth on mineral deficient soils. Animals ranging over these pastoral areas and subsisting exclusively on such mineral deficient herbage, display a low rate of growth and production compared with what is possible on good cultivated pastures. With this decreased growth rate are usually associated lowered fertility and susceptibility to various forms of disease.

During 1926, the committee appointed by the Economic Advisory Council to consider the question of the mineral content of natural pastures recommended that practical investigations should be carried out in a suitable colony or dependency with the view of ascertaining whether the nature of such deficiencies could be determined and the diseases due to them prevented. Following this recommendation, a scheme of research was inaugurated which serves as a model of successful co-operative effort. Kenya Colony was selected as the site of the investigations, and Dr. J. B. Orr, director of the Rowett Research Institute, Aberdeen, assumed the general scientific direction. The Empire Marketing Board rendered signal help by placing generous funds at his disposal. Close and enthusiastic co-operation was established between his own staff of research assistants, some of whom worked in Aberdeen and others in Kenya, and the staff of the Agricultural Department in Kenya Colony. In addition, valuable assistance was given by settlers in the colony, many of whom provided animals and facilities for feeding experiments.

The initial outcome of these important investigations is revealed in the Report now before us, which has been drawn up by Dr. Orr in association with Mr.
A. Holm, director of agriculture, Kenya.* Though the main scheme of work is still in its early stages, the results so far obtained are of the highest economic significance and amply justify the trouble which has been taken to secure them.

It has been shown that the most striking deficiency in the natural pastures of Kenya is that of phosphorus. Indeed, in one district, Molo, the deficiency of this element is as great as that found in certain areas of South Africa, where it is the cause of disease in cattle. On the other hand, in another district, Naivasha, the pasturage, apart from deficiency in sodium and chlorine, is as rich as the herbage of good British cultivated pastures. The application of different fertilisers in the most deficient area increased the yield of herbage from 25 per cent, where common salt only was used, to as much as 400 per cent where nitrogenous and phosphatic fertiiisers were employed. The provision of small amounts of the deficient minerals to animals grazing these areas was followed by an increase of 30 per cent in the yield of dairy cows, 10 per cent in the rate of growth of lambs, and about 10 per cent in the weight of the fleeces of sheep.

It was discovered that 'Nakuruitis', a local disease resembling the 'bush-sickness' of New Zealand, could be prevented by allowing animals access to a mixture of common salt and iron oxide. This method of prevention is now being applied with successful results on several farms in Kenya, oxen being kept in good condition for at least a year, whereas formerly, without the use of this simple salt lick, it was impossible to keep them free from the disease for longer than six months without sending them away for a period of grazing in another district.

\section{H. E. WoOdman.}

* Economic Advisory Council: Committee on the Mineral Content of Natural Pastures. Sixth Report. Pp. 66. (London: H.M. Stationery Office, 1931.) 1s. net.

\section{Medicinal Cod Liver Oil.*}

ATHOUGH the medicinal value of cod liver oil has been known for 150 years, it is only recently that it has been attributed to the presence of vitamins $A$ and $D$. It is now known, moreover, that different samples of oil vary widely in their vitamin potency as well as in their more obvious chemical and physical characteristics. The principles underlying the production of a fine medicinal oil of high activity should be established so that consumers can always be certain of obtaining full benefit from its administration. The recently issued Empire Marketing Board Report by Profs. J. C. Drummond and T. P. Hilditch provides specifications for cod liver oil which are based on the examination of a large number of samples over several years, and makes recommendations for suitable methods of manufacture.

The investigators examined oils from Newfoundland, Scotland and the North Sea, Iceland, and Norway, obtained at different seasons, for vitamin potency, colour, and fatty acid content, and estimated their saponification and iodine values : oils from other fish were also compared with cod liver oil. Vitamin A was estimated both by the growth test on rats and by the antimony trichloride colour test : in a series of oils very fair agreement between the two methods was

* The Relative Values of Cod Liver Oils from Various Sources. By Prof. T. Drionmond and Prof. T.P. Hilditch (E.M. B. 35.) Pp. 129. (Loniton: H.M. Stationery Office, 1930.) 18. net. obtained, so that the quicker and simpler colour test was used during the greater part of the research as an estimate of the vitamin A potency. Using standard conditions, the results can be expressed in Lovibond blue units; it was not found possible to express the results of assays by the biological method in units, owing to the errors of the animal test. Vitamin D was estimated by the degree of deposition of calcium at the ends of the long bones of rachitic rats as observed under X-rays and following staining with silver nitrate (the 'line test'): the assays were carried out against the standard preparation of irradiated ergosterol employed by the Pharmaceutical Society and the results expressed in terms of the Coward antirachitic unit.

The Newfoundland and Icelandic oils had the highest vitamin potency, the Norwegian the lowest, with the Scottish intermediate, but usually of the same order of activity as the latter. The vitamin A and vitamin $\mathrm{D}$ potencies were usually parallel.

A detailed chemical examination of the constituent fatty acids of cod liver and other oils was made : the methods and results have been published in full in the Biochemical Journal, by Guha, Hilditch, and Lovern (vol. 24, p. $266 ; 1930$ ) and by Lovern (ibid., p. 866). The general composition of the fatty acids of cod liver oil is: stearic and myristoleic acids, traces only; myristic acid, 3-7 per cent; palmitic acid, 
7-13 per cent; palmitoleic acid, 13-20 per cent; oleic and linoleic acids, 18.33 per cent; unsaturated acids containing 20 carbon atoms, $19-32$ per cent; unsaturated acids containing 22 carbon atoms, $10-19$ per cent. The depth of the yellow colour of the oil was found to be roughly proportional to its vitamin potency.

The variations in potency of different samples are not apparently directly dependent on the age or sexual condition of the fish, but on the character and amount of the food eaten, which varies according to the season. On the other hand, examination of the fish and several crustacea which form the food supply of the cod showed them to be singularly devoid of both vitamins. It has been shown that phytoplankton synthesise vitamin A (Ahmad, Biochem. Jour., vol. 24 , p. $860 ; 1930)$ : zooplankton contain none and neither contain appreciable quantities of vitamin $\mathbf{D}$, although there may be small amounts present in zooplankton. There is no evidence that the cod can synthesise either, though the possibility cannot be excluded. The alternative is that the fish retains the small amounts in its food in its liver, so that over a course of months with a plentiful food supply this organ comes to contain considerable amounts. The potency of the oil varies inversely with the amount obtained from the liver: prior to spawning there is a utilisation of the liver fat, especially in the female; but the vitamin store is not proportionally depleted, so that the oil has a high potency. The authors believe this to be the explanation of the high vitamin content of Newfoundland oil.

From an examination of the effects of different methods of manufacture upon the palatability, keeping properties, and potency of the oil, the following procedure is recommended: Livers should be fresh and steamed immediately they have been removed from the fish. Steam at 60-100 lb. pressure per sq. in. gives better results than steam at a lower pressure, and the process should not be too short. Subsequent refining should be restricted to removal of moisture, debris, and stearine by chilling and centrifuging or pressure; finally, medicinal oils should be stored in vessels impermeable to light and containing as little free air space as possible. Deterioration is caused by the activity of the liver enzymes ; hence the necessity for using only fresh material and for adequate steaming to destroy them. High pressure steam also gives a higher yield of oil. It was found that the replacement of air in the storage casks by an inert gas was difficult to carry out properly and did not increase the keeping properties of the oil. Protection from light and undue exposure to air is, however, of great importance.

As a result of their work, the authors put forward the following specifications for medicinal cod liver oil : The colour, when measured in a 1 -in. cell, should not be greater than 10 yellow Lovibond units and 0.5 red unit. The free fatty acid (as oleic acid) should not be greater than 0.5 per cent, preferably below 0.3 per cent. The unsaponifiable matter should not be more than 1.5 per cent, preferably below 1 per cent. The vitamin A colour test should give a higher value than 7 blue Lovibond units, when carried out by the authors' technique. For oil intended for farm-stock, the colour and free acidity may be slightly greater but the amount of unsaponifiable matter and vitamin A present should be the same. There appears to be no doubt that oils from Scotland and, especially, Newfoundland are capable of meeting these specifications.

\section{Mosquito Control.*}

r HE Report for 1930 of the British Mosquito Control 1 Institute, Hayling Island, Hampshire, is a record of two and a half years' work, the previous Report having been presented in June 1928. The Institute, it may be added, was built and equipped in 1925 by Mr. John F. Marshall, who has since occupied the position as director without remuneration. It was incorporated by licence of the Board of Trade in February 1927 and, by a deed executed at the same time, the building and its equipment were leased to trustees for a term of years. No financial aid is received from any official funds, and the income of the Institute is derived solely from the results of its own activities and from subscriptions and donations. Funds are greatly needed in order to enable the work to become more self-supporting, since the present income falls a long way short of covering expenditure.

The activities of the Institute have markedly increased since the issue of the last Report, and the interest shown by the outside public in this work is borne out by the fact that more than 1400 visitors (scientific and others) inspected the museum and laboratory during 1930. Advisory work relating to mosquitoes, their identification and control, is carried out by means of inspection and by correspondence. Inspections are generally undertaken by the director's assistant at a pre-arranged charge which includes the submission of a report and the recommendation of remedial measures. Various lines of investigation have been carried out during the period under review, including tests of fly-killing preparations and of cresolcontaining larvicides, at the request of commercial

* British Mosquito Control Institute. Report of the Director. Presented at the Fourth Annual General Meeting, Dec. 9, 1930. 16 pp. and 30 illugtrations. Hayling Island, Hampshire. firms. A study has also been commenced with regard to the breeding of arboreal mosquitoes in cavities (natural and artificial) in sawn-off parts of trees of different species.

In June 1929 a special malaria course, arranged in connexion with the League of Nations and the London School of Tropical Medicine, included in its programme a three-day visit to the Institute for laboratory and field instruction. A number of medical officers took part in this work. In September 1930 a week's course, of a tentative character, on mosquito research for university students was given, and was sufficiently appreciated to warrant arrangements being made for its repetition during the present year. Among other educational activities, the director has delivered lectures on mosquito control to various institutions, etc., while demonstrations have been conducted at a number of scientific meetings, exhibitions, etc. By way of technical apparatus, the advances made in connexion with photomicrography and stereograph methods are described in the Report. Mention needs also to be made of the small but growing library of the Institute: a number of new books have been added both by gift and by purchase, while certain of the more important periodicals are taken in regularly. The director of the Institute is to be congratulated upon the initiative and energy he is giving to the development of his charge and on the progress so far achieved.

Scientific societies, educational bodies, local authorities, and other associations desirous of supporting this useful work may become ' collective' members. Members (whether individual or collective) subscribe one guinea per annum and receive a copy of the publications of the Institute. 